\title{
ТЕРМИЧЕСКОЕ РАСТВОРЕНИЕ УГЛЯ ГЖ В СРЕДЕ РАЗЛИЧНЫХ ПАСТООБРАЗОВАТЕЛЕЙ
}

\author{
(С) 2018 г. П. Н. Кузнецов 1 ,* А. В. Обухова ${ }^{1, *}$, Л. И. Кузнецова ${ }^{1}$, Ф. А. Бурюкин ${ }^{2, * *}$, \\ Н. И. Павленко ${ }^{1, *}$, С. М. Колесникова ${ }^{1, *}$, Е. С. Каменский ${ }^{1, *}$, Н. В. Перминов ${ }^{1, *}$ \\ ${ }^{1}$ ФГБУН Институт химии и химической технологии СО РАН, \\ Федеральный исследовательский иентр “Красноярский научный центр СО РАН”, Красноярск, Россия \\ ${ }^{2}$ Сибирский федеральный университет, Красноярск, Россия \\ *e-mail:kpn@icct.ru \\ *e-mail:lab9team@rambler.ru \\ **e-mail:fburyukin@sf-kras.ru \\ Поступила в редакцию 25.01.2018 г.
}

\begin{abstract}
Изучен процесс термического растворения угля марки 1ГЖ в среде различных технических пастообразователей: в смоле коксования (CK), антраценовой фракции смолы коксования (АФСК), тяжелой смоле полукоксования (ТСПК) и нефтяном газойле (НГ). Установлено, что присутствие в растворителе поликонденсированных молекул с низкой степенью замещения ароматических колец и соединений, обладающих водорододонорной и сольватирующей активностью, способствует эффективному протеканию процесса терморастворения каменного угля при невысокой температуре $380^{\circ} \mathrm{C}$. Наиболее высокие выходы растворимых веществ (78-85\%) достигнуты при проведении процесса в среде АФСК и СК.
\end{abstract}

Ключевые слова: каменный уголь, пастообразователь, терморастворение, пекоподобный продукт DOI: $10.1134 / \mathrm{S} 0023117718050067$

\section{ВВЕДЕНИЕ}

Связующие материалы - важный компонент при производстве большинства видов высокотехнологичных углеродных материалов. Их качество в значительной мере определяет уровень физикомеханических характеристик получаемого продукта. В качестве связующего широко используется каменноугольный пек - побочный продукт процесса коксования каменных углей при получении кокса для нужд черной металлургии. Сoстав пека представлен сложной смесью поликонденсированных ароматических углеводородов и гетероциклических соединений $[1,2]$.

Современные направления модернизации процессов черной металлургии, предусматривающие снижение расхода кокса, приводят к снижению выработки каменноугольной смолы и, как следствие, пека. В настоящее время отечественная коксохимическая промышленность не обеспечивает потребности в пеке, особенно возрастающие потребности алюминиевой промышленности для производства анодов. Важно также отметить непрерывное увеличение требований к качеству пека в различных отраслях промышленности и его ограниченный ассортимент, что, в свою очередь, тормозит развитие производства прогрессивных углеродных материалов [2, 3]. Отмеченные разнонаправленные тенденции производства пека и потребности в нем характерны не только для России, но и для многих стран, в совокупности они выдвигают задачу создания нового способа получения заменителя каменноугольного пека, минуя процесс коксования.

В настоящее время создаваемые производства альтернативных пеков базируются в основном на нефтяном сырье [4-6]. Перспективным способом получения альтернативного пека из угля является термохимическое превращение в среде органического растворителя [7, 8]. Традиционно этот процесс ориентирован на достижение глубокой деструкции органической массы угля с получением светлых углеводородных фракций топливного назначения. При изменении параметров процесса можно получать поликонденсированные ароматические углеводородные продукты, которые составляют основу пека [9-13].

Этот подход базируется на том, что в составе органической массы углей изначально присутствуют фрагменты, включающие полициклические ароматические молекулы. В структуре угля они ассоциированы посредством множественных межмолекулярных взаимодействий и мостико- 
вых сшивок в крупные молекулы, олигомеры и мультимеры. Роль сшивок играют в основном эфирные и короткие метиленовые группы. Прочность таких сшивок зависит, в частности, от степени конденсированности ароматических фрагментов [14]. В органической массе каменных углей средней и высокой степени метаморфизма с повышенным содержанием полиароматических фрагментов значительную роль в ассоциации играют невалентные межмолекулярные взаимодействия различной природы [15]. Нарушение межмолекулярной ассоциации сопровождается размягчением угля и его переходом в пластическое состояние. В присутствии растворителя с сольватирующими свойствами пластическая масса угля может переходить в растворимое (или коллоидное) состояние. Содержащиеся в ней поликонденсированные ароматические углеводороды могут служить источником получения заменителя каменноугольного пека.

Опубликованные в литературе данные показывают, что выход и состав продуктов в процессе термического растворения сложным образом зависят от свойств угля, растворителя и температуры. Так, по данным [8, 16], наиболее высокий выход растворимых продуктов достигался при терморастворении каменных углей средней стадии метаморфизма с содержанием углерода около 85\%. Продукты содержали в основном высококипящие фракции.

Цель данной работы - исследование влияния технических полиароматических пастообразователей на выход и состав продуктов терморастворения каменного угля.

\section{ЭКСПЕРИМЕНТАЛЬНАЯ ЧАСТЬ}

В работе использовали каменный уголь Чаданского месторождения (ОOО “Тувинская горнорудная компания"). По паспортным данным, он соответствовал марке газовый жирный 1ГЖ с толщиной пластического слоя 19-20 мм и температурой размягчения $340-350^{\circ} \mathrm{C}$. Выход летучих веществ составлял $35.8 \%$, содержание минеральных веществ - 5.2\%. Уголь характеризовался следуюшим элементным составом, мас. \%: углерод 84.0, водород 5.4, азот 1.1, сера 0.6 и кислород 8.9. Отобранную пробу угля измельчали (фракция менее 1 мм со средним размером частиц 0.4 мм) и высушивали в вакуумном шкафу при $85^{\circ} \mathrm{C}$.

В качестве растворителей-пастообразователей использовали 1-метилнафталин (марки “технический” с содержанием основного вещества 95\%) и технические углеводородные фракции: тяжелую смолу полукоксования (ТСПК) каменного угля марки Д - завод полукоксования, г. Ленинск-Кузнецкий; смолу коксования (СК) - АО "Алтай-Кокс", г. Заринск; антраценовую фрак- цию смолы коксования (АФСК) - АО “Кокс", г. Кемерово; нефтяной газойль каталитический (НГ) - сырье для производства техуглерода, марки А - АО Газпромнефть-Омский НПЗ, г. Омск.

Элементный анализ угля и растворителя осуществляли на анализаторе Flash $E A^{T M} 1112$ (в Красноярском региональном центре коллективного пользования Федерального исследовательского центра "Красноярский научный центр Сибирского отделения Российской академии наук” (КРЦКП ФИЦ КНЦ СОРАН)).

Особенности молекулярного состава органической массы угля (ОМУ), растворителей и продуктов характеризовали по ИК-спектрам, которые снимали на ИК-Фурье-спектрометре Bruker Tensor-27 (КРЦКП ФИЦ КНЦ СОРАН). Характеристики пространственного строения угля и получаемых твердых продуктов определяли по дифрактограммам, которые записывали на дифрактометре PANalytical X'Pert PRO в CuK $K_{\alpha}$-излучении. Определение параметров структуры осуществляли по методикам работ [17, 18].

Процесс терморастворения угля проводили на экспериментальной установке, оборудованной автоклавом объемом 2 л с механической мешалкой (скорость вращения мешалки 120-160 об/мин) при температуре $380^{\circ} \mathrm{C}$ и соотношении уголь : $:$ растворитель $=1: 2$. По окончании реакции температуру снижали, после чего содержимое автоклава в расплавленном виде выгружали через нижний сливной патрубок в обогреваемый цилиндр-отстойник, где при температуре $250^{\circ} \mathrm{C}$ происходило осаждение твердых частиц (минеральных веществ и угольного остатка). После отстаивания, охлаждения и отделения донного зольного осадка получали обеззоленный пекосодержащий экстракт. Групповой состав полученных экстрактов характеризовали по растворимости в толуоле и хинолине стандартными методами по ГОСТ 10200-83. Температуру размягчения определяли по ГОСТ 9950-83 (метод “кольцо и шар").

\section{РЕЗУЛЬТАТЫ И ОБСУЖДЕНИЕ}

В ИК-спектре угля (рис. 1) наблюдались интенсивные полосы поглощения (п.п.) валентных колебаний алифатических $\mathrm{C}-\mathrm{H}$-связей в области 2800-3000 $\mathrm{cm}^{-1}$ и деформационных колебаний при 1460-1370 $\mathrm{cm}^{-1}$. Полосы с максимумами при 3048 и $1600 \mathrm{~cm}^{-1}$ и в области 700-900 см ${ }^{-1}$ отражали присутствие различных ароматических структур. Широкая высокочастотная п.п. с максимумом при $3450 \mathrm{~cm}^{-1}$ обусловлена водородосвязанными фенольными О-Н-группами. Анализ других кислородсодержащих фрагментов по поглощению в области $1300-1000 \mathrm{~cm}^{-1}$ затруднен изза наложения п.п. от минеральных веществ. 


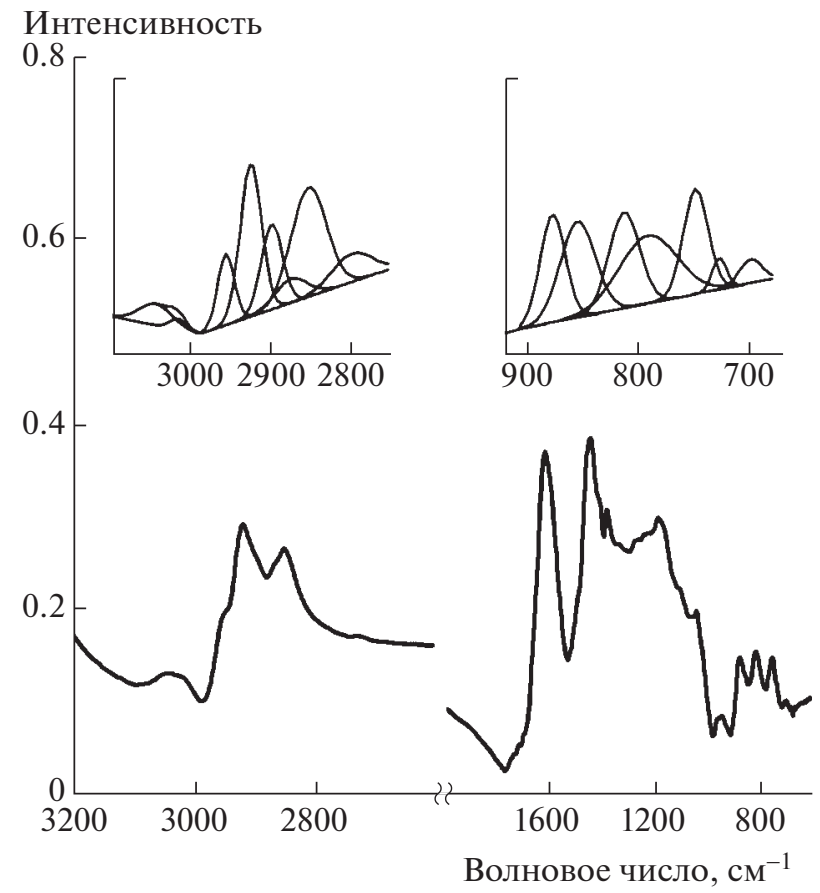

Рис. 1. ИК-спектр угля 1ГЖ.

Путем разложения спектра определены следующие показатели молекулярного состава угля: индекс ароматичности $H_{a r}$, степень замещения ароматических колец и соотношение групп $\mathrm{CH}_{3} / \mathrm{CH}_{2}$ в молекулах. Индекс ароматичности $H_{a r}$ оценивали по отношению интегральной интенсивности п.п. валентных колебаний ароматических С-Н-связей в области $3100-3000 \mathrm{~cm}^{-1}\left(A_{a r}\right)$ и алифатических С-H-связей в области 3000$2800 \mathrm{~cm}^{-1}\left(A_{a l}\right)$. Показатель степени замещения ароматических колец оценивали по отношению интенсивности п.п. при $730 \mathrm{~cm}^{-1}$ (малозамещенные ароматические молекулы) к суммарной интенсивности п.П. в области $900-700 \mathrm{~cm}^{-1}\left(A_{700-900}\right)$ (ароматические молекулы с различной степенью замешения). Соотношение групп $\mathrm{CH}_{3} / \mathrm{CH}_{2}$ определяли по отношению интенсивностей п.п. при 2958 и $2920 \mathrm{~cm}^{-1}$. При оценке указанных показателей учитывали [19], что отношение коэффициента экстинкции для валентных колебаний аро-

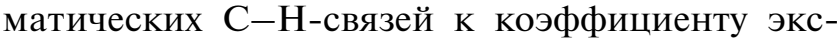
тинкции для алифатических $\mathrm{C}-\mathrm{H}$-связей для каменных углей составляет в среднем 0.22 , а для $\mathrm{C}-\mathrm{H}$-связей в $\mathrm{CH}_{2}$-группах и в $\mathrm{CH}_{3}$-группах 0.5 . Расчет проводили по уравнениям (1) и (2).

Индекс ароматичности

$$
H_{a r}=\frac{A_{a r} / 0.22 A_{a l}}{1+\left(A_{a r} / 0.22 A_{a l}\right)} \times 100, \% .
$$

Соотношение

$$
\mathrm{CH}_{3} / \mathrm{CH}_{2}=0.5 \times\left(A_{2958 \mathrm{~cm}^{-1}} / A_{2920 \mathrm{~cm}^{-1}}\right) .
$$

Интенсивность

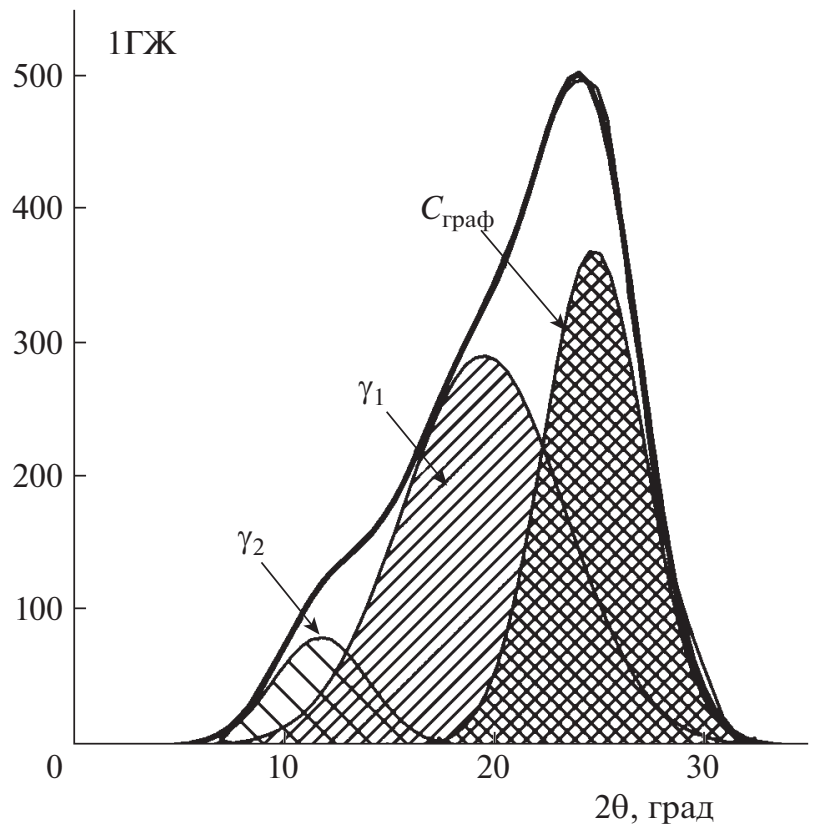

Рис. 2. Фрагмент дифрактограммы угля 1 ЖЖ: $C_{\text {граф }}-$ сравнительно упорядоченная графитоподобная компонента; $\gamma_{1}$ и $\gamma_{2}-$ мало упорядоченные структурные компоненты ОМУ.

По данным анализа, индекс ароматичности $H_{a r}$ и степень замещения ароматических колец молекул органической массы угля составляли 25 и $0.20 \%$ соответственно. Соотношение $\mathrm{CH}_{3} / \mathrm{CH}_{2}$ в алифатических фрагментах -0.18 .

На дифрактограмме угля наблюдались широкие рефлексы в областях $2 \theta$ от 7 до $34^{\circ}$ и от 34 до $52^{\circ}$, обусловленные определенным упорядочением фрагментов органической массы. На рис. 2 приведен фрагмент дифрактограммы с разложением асимметричного рефлекса в области $2 \theta$ от 7 до $34^{\circ}$ на три гауссианы - сравнительно упорядоченную графитоподобную компоненту $\left(C_{\text {граф }}\right)$ с максимумом при $2 \theta=25^{\circ}$, содержащую упакованные в пачки плоские полиароматические молекулы, и две менее упорядоченные $\gamma$-компоненты, расположенные на периферии графитоподобных пакетов с максимумами при $2 \theta=17^{\circ}$ и $9^{\circ}[17$, 18]. Согласно [17], $\gamma_{1}$-компонента $\left(2 \theta=17^{\circ}\right)$ представляет алкилароматические и нафтенароматические структуры, а $\gamma_{2}$-компонента $\left(2 \theta=9^{\circ}\right)-$ наименее упорядоченные парафиновые и кислородсодержащие структуры.

В структуре угля преобладали малоупорядоченные $\gamma$-компоненты (59\%). Содержание графитоподобной компоненты составляло $41 \%$, в среднем пакеты состояли из 4.4 слоев-графенов с расстоянием между ними $3.6 \AA$ и диаметром около $19 \AA$, что может соответствовать средней полициклической ароматической молекуле с 6-8 кон- 
Таблица 1. Характеристика применяемых в процессе растворителей

\begin{tabular}{|c|c|c|c|c|c|}
\hline \multirow{2}{*}{ Растворитель } & \multicolumn{3}{|c|}{ Элементный состав, мас. \% } & \multirow{2}{*}{$\begin{array}{c}\text { Температурный интервал } \\
\text { выделения летучих } \\
\text { веществ, }{ }^{\circ} \mathrm{C}\end{array}$} & \multirow{2}{*}{$\begin{array}{c}\text { Температура } \\
\text { максимальной скорости } \\
\text { выделения летучих, }{ }^{\circ} \mathrm{C}\end{array}$} \\
\hline & $\mathrm{C}$ & $\mathrm{H}$ & $\mathrm{N}+\mathrm{S}+\mathrm{O}$ & & \\
\hline ТСПК & 83.7 & 7.0 & 9.3 & $150-350$ & 290 \\
\hline АФСК & 87.6 & 5.2 & 7.2 & $150-350$ & 295 \\
\hline CK & 91.1 & 5.5 & 3.4 & $350-550$ & 443 \\
\hline НГ & 90.6 & 8.4 & 1.0 & $307-508$ & 400 \\
\hline
\end{tabular}

денсированными бензольными кольцами. Малоупорядоченные $\gamma$-компоненты отличались более рыхлой упаковкой со средним расстоянием между нафтенароматическими и ароматическими фрагментами $6.5 \AA$.

Характеристики растворителей-пастообразователей представлены в табл. 1. Содержание водорода увеличивалось в ряду АФСК $<$ CK $<$ ТСПК $<$ НГ $<1$-метилнафталин. Значительно различались температурные интервалы выделения летучих веществ, определенные по данным термического анализа и фракционной разгонки, 1-Метилнафталин с двумя конденсированными ароматическими кольцами имел наиболее низкую температуру кипения $\left(245^{\circ} \mathrm{C}\right)$. Для ТСПК и АФСК максимальная скорость выделения летучих веществ соответствовала температуpe $290-295^{\circ} \mathrm{C}$, практически полное улетучивание

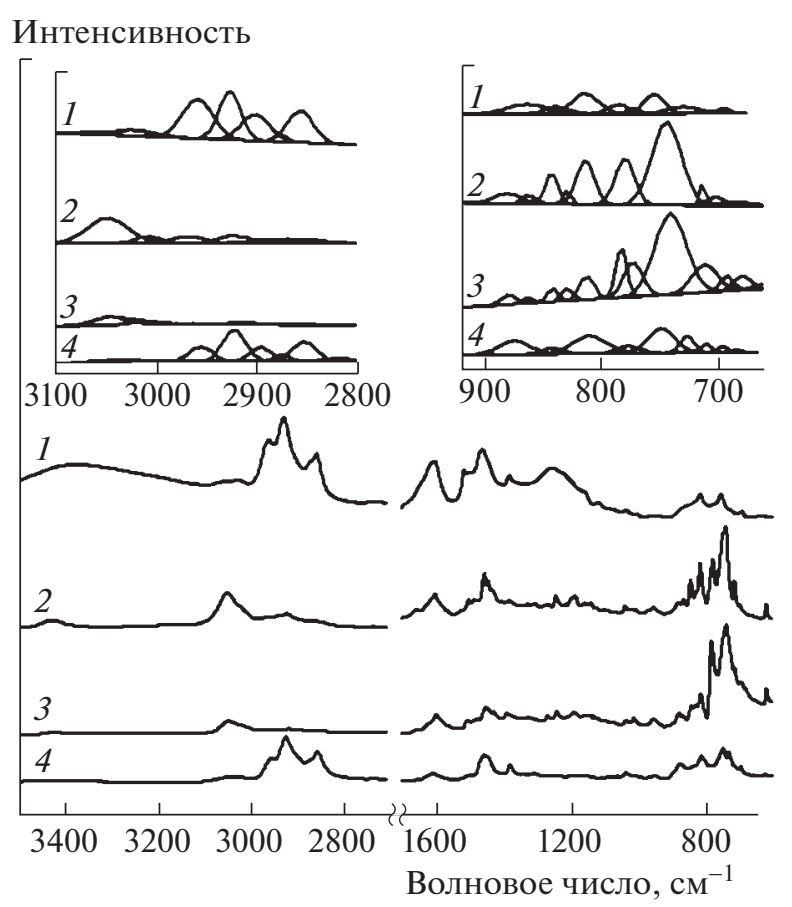

Рис. 3. ИК-спектры растворителей, использованных в процессе терморастворения угля: 1 - ТСПК; 2-АФСК; 3- СК; 4-НГ. достигалось при $350^{\circ} \mathrm{C}$, в тигле оставался коксовый остаток в количестве 2-3\%. Температура начала кипения нефтяного газойля составляла $221^{\circ} \mathrm{C}, 90 \%$ выкипало при $490^{\circ} \mathrm{C}$. Смола коксования, содержащая сложную смесь поликонденсированных ароматических молекул, отличалась широким температурным интервалом выделения летучих веществ вплоть до $508^{\circ} \mathrm{C}$.

На рис. 3 представлены ИК-спектры, показывающие разный молекулярный состав растворителей. Для всех образцов наблюдались п.П. при

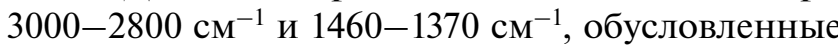
присутствием алифатических соединений. Полосы при 3048, 1600 и 900-700 см-1 разной интенсивности указывали на присутствие ароматических соединений. Спектр для ТСПК отличался широкой и интенсивной полосой с максимумом при $3400 \mathrm{~cm}^{-1}$ (рис. 3, кривая 1), отвечающей за присутствие фенольных гидроксилов. В спектре АФСК полоса с максимумом при $3425 \mathrm{~cm}^{-1}$ имела сравнительно низкую интенсивность, что указывало на невысокую концентрацию фенольных гидроксилов и азотсодержащих гетероциклических соединений (таких, как карбазол, хинолин, их производных). Подобные вещества обладают сольватирующими свойствами и могут способствовать переходу в раствор фрагментов угля при его терморастворении. Нефтяной газойль содержал преимущественно алифатические углеводороды, практически отсутствовали кислород- и азотсодержащие соединения.

Рассчитанные по спектрам характеристики молекулярного состава приведены в табл. 2. Наиболее высокую ароматичность $H_{a r}$ и наиболее низкую степень замещения ароматических колец имели АФСК и СК. Смола ТСПК имела низкую ароматичность $\left(H_{a r}=27 \%\right)$ и наиболее высокое содержание метиленовых цепочек (соотношение $\left.\mathrm{CH}_{3} / \mathrm{CH}_{2}=0.54\right)$, чем остальные растворители. Наиболее низкой степенью ароматичности отличался НГ. Отметим, что в ряду растворителей ароматичность 1-метилнафталина (исходя из числа алифатических и ароматических $\mathrm{C}-\mathrm{H}$-связей в молекуле) составляла $70 \%$.

Термическое растворение угля. В табл. 3 приведены показатели терморастворения угля в раз- 
Таблица 2. Характеристики молекулярного состава растворителей по данным ИК-спектроскопии

\begin{tabular}{c|c|c|c}
\hline Растворитель & Ароматичность, \% $H_{a r}$ & Степень замещения $\left(A_{730} / A_{700-900}\right)$ & ${\text { Отношение } \mathrm{CH}_{3} / \mathrm{CH}_{2}}^{\text {ТСПК }}$ \\
\hline АФСК & 27 & 0.20 & 0.54 \\
СК & 87 & 0.47 & 0.29 \\
НГ & 96 & 0.48 & 0.20 \\
\hline
\end{tabular}

Таблица 3. Сопоставление показателей превращения ОМУ в процессе термического растворения в различных растворителях

\begin{tabular}{|c|c|c|c|c|c|}
\hline \multirow{2}{*}{ Растворитель } & \multirow{2}{*}{$\begin{array}{c}\text { Конверсия } \\
\text { угля, \% }\end{array}$} & \multicolumn{2}{|c|}{$\begin{array}{c}\text { Содержание нерастворимых } \\
\text { веществ, мас. \% }\end{array}$} & \multirow{2}{*}{$\begin{array}{c}\text { Внешний вид } \\
\text { продукта }\end{array}$} & \multirow{2}{*}{$\begin{array}{c}\text { Температура } \\
\text { размягчения, }{ }^{\circ} \mathrm{C}\end{array}$} \\
\hline & & $\begin{array}{c}\text { в толуоле } \\
(\alpha-ф р а к ц и я)\end{array}$ & $\begin{array}{c}\text { в хинолине } \\
\left(\alpha_{1} \text {-фракция) }\right.\end{array}$ & & \\
\hline 1-Метилнафталин & 50 & 32 & 25 & Вязкожидкая масса & - \\
\hline ТСПК & 0 & 0 & 70 & Твердый, непластичный & $>130$ \\
\hline АФСК & 85 & 30 & 6 & Твердый, пластичный & 76 \\
\hline CK & 78 & 35 & 7 & То же & 86 \\
\hline НГ & 76 & 23 & 8 & Вязкожидкая масса & - \\
\hline
\end{tabular}

личных растворителях при температуре $380^{\circ} \mathrm{C}$. Видно, что высококипящие растворители АФСК, СК и НГ обеспечивали достаточно высокую степень превращения органической массы угля в растворимые вещества. В среде АФСК конверсия угля достигала $85 \%, 1$-метилнафталин был менее эффективен, а в среде ТСПК растворимые продукты из угля вовсе не образовывались, напротив, в продуктах повышалось количество нерастворимых веществ. Выход газообразных продуктов во всех случаях не превышал $1.0 \%$. В основном образовывались $\mathrm{CO}_{2}, \mathrm{H}_{2} \mathrm{~S}, \mathrm{H}_{2}$ и немного $\mathrm{CO}$ и $\mathrm{CH}_{4}$.

Растворимые продукты, за исключением продуктов, полученных в 1-метилнафталине и НГ, представляли твердые вещества, температура размягчения которых составляла от 76 до $>130^{\circ} \mathrm{C}$. По данным анализа группового состава, в продуктах, полученных в АФСК, СК и НГ, содержание веществ, не растворимых в хинолине, не превышало $8 \%$, в 1-метилнафталине - 25\%. Продукт после реакции угля с ТСПК на $70 \%$ состоял из нерастворимых в хинолине веществ, в то время как в исходной углемасляной пасте (т.е. до реакции) их доля составляла 33\%. Это свидетельствует о том, что в ходе реакции смола ТСПК в значительной степени подвергалась поликонденсации с веществами органической массы угля с образованием нерастворимых веществ. Таким образом, в исходном виде она практически непригодна в качестве растворителя для данного процесса.

В ИК-спектрах полученных пекоподобных продуктов (рис. 4) наблюдались интенсивные полосы поглощения алифатических структур в об- ласти 3000-2800 см -1 , при 1460-1370 $\mathrm{cm}^{-1}$ и полосы поглощения для ароматических соединений в области 3100-3000 см $\mathrm{cm}^{-1}, 1600 \mathrm{~cm}^{-1}$ и при 900-

Интенсивность
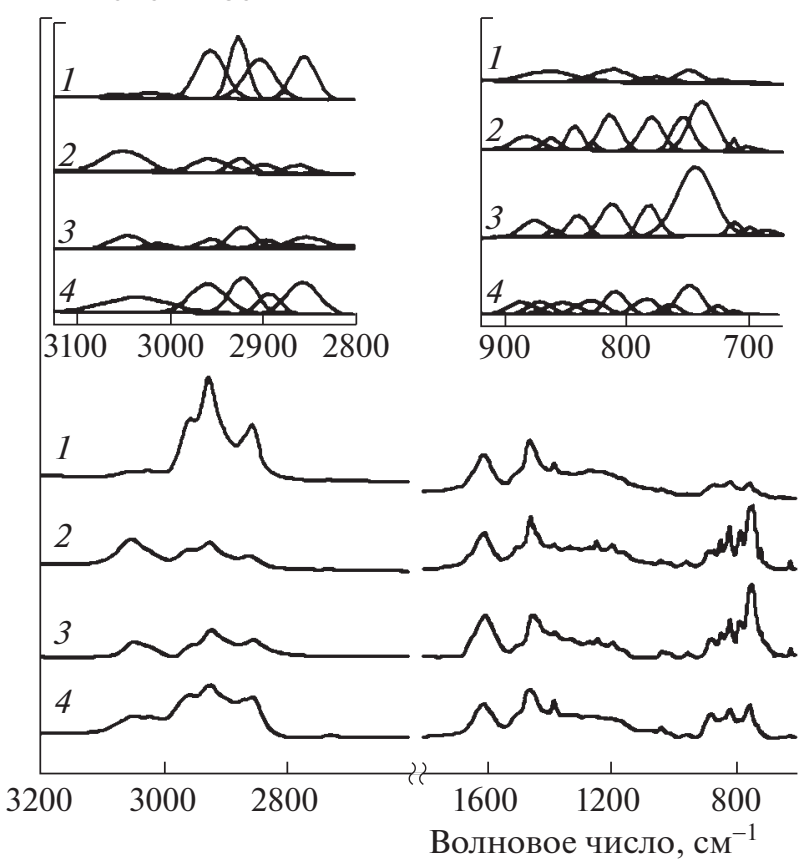

Рис. 4. ИК-спектры обеззоленного продукта, полученного в процессе терморастворения угля в различных растворителях: 1 - ТСПК; 2 - АФСК; 3 - СК; $4-\mathrm{H} \Gamma$. 
Таблица 4. Характеристики молекулярного состава продуктов термического растворения угля по данным ИКспектроскопии

\begin{tabular}{c|c|c|c}
\hline Растворитель & Ароматичность $\left(H_{a r}\right), \%$ & Степень замещения $\left(A_{730} / A_{700-900}\right)$ & Отношение $\mathrm{CH}_{3} / \mathrm{CH}_{2}$ \\
\hline ТСПК & 22 & 0.19 & 0.61 \\
АФСК & 72 & 0.42 & 0.24 \\
СК & 63 & 0.47 & 0.19 \\
НГ & 30 & 0.27 & 0.25 \\
\hline
\end{tabular}

$700 \mathrm{~cm}^{-1}$. Рассчитанные по ИК-спектрам характеристики молекулярного состава сопоставлены в табл. 4. Индекс ароматичности $H_{a r}$ уменьшался в ряду растворителей в следующем порядке: АФСК $>\mathrm{CK}>\mathrm{HГ}$, отношение $\mathrm{CH}_{3} / \mathrm{CH}_{2}$ составляло от 0.19 до 0.25. Продукт, полученный в среде НГ, отличался невысокой ароматичностью $\left(H_{a r}=30 \%\right)$, а ароматические кольца имели повышенную степень замещения.

Таким образом, результаты по терморастворению угля показали, что эффективность процесса в большой степени зависит от типа растворителя, его химической природы. Наиболее эффективно процесс протекал в АФСК и СК, молекулярный состав которых характеризовался высокой ароматичностью, низкой степенью замещения ароматических колец. В их составе обычно в существенном количестве содержатся производные хинолина, карбазола, индола, фенола [20]. Такие соединения обладают сольватирующими свойствами по отношению к углю и продуктам деструкции и способствуют их солюбилизации и переходу в раствор. В большом количестве содержатся поликонденсированные ароматические углеводороды такие, как фенантрен, антрацен, пирен, и в незначительном количестве - частично гидрированные ароматические углеводороды (производные пирена, антрацена). Такие молекулы содержат активные атомы водорода и способны стабилизировать радикальные частицы, образующиеся при термолизе ковалентных связей. Важно также отметить, что использованный уголь имел сравнительно низкую температуру размягчения. В условиях реакции частицы угля в среде жидкофазного пастообразователя находились в пластическом состоянии, что способствовало эффективному взаимодействию с молекулами растворителя. Таким образом, благоприятное сочетание свойств пастообразователей и угля обусловливало наиболее эффективное протекание процесса терморастворения в среде АФСК и СК с образованием ароматических углеводородных продуктов. По составу они характеризуются высоким содержанием полиароматических веществ и могут служить источником получения заменителя каменноугольного пека.

\section{ВЫВОДЫ}

В результате проведенных исследований определены основные показатели термического растворения каменного угля марки 1ГЖ в среде различных технических полиароматических растворителей-пастообразователей.

Установлено, что наиболее эффективно процесс термического растворения протекает в среде смолы коксования и антраценовой фракции смолы коксования с выходом хинолин-растворимых продуктов из угля до 78-85\%.

Полученный продукт терморастворения представлял твердую пекоподобную массу с температурой размягчения $76-86^{\circ} \mathrm{C}$, содержащую преимущественно хинолин-растворимые вещества, содержание хинолин-нерастворимых веществ не превышало 7-8\%. По составу полученные продукты характеризуются высоким содержанием полиароматических веществ и могут служить источником получения заменителя каменноугольного пека.

Применение нефтяного газойля в качестве растворителя менее эффективно, тяжелая смола полукоксования для этих целей практически непригодна из-за интенсивно протекающих процессов поликонденсации.

\section{СПИСОК ЛИТЕРАТУРЫ}

1. Granda M., Blanco C., Alvarez P., Patrick J.W., Menéndez R. // Chem. Rev. 2014. V. 114. P. 1608.

2. Костиков В.И., Самойлов В.М., Бейлина Н.Ю., Остронов Б.Г. // Рос. хим. журн. 2004. № 5. С. 64.

3. Рудыка В.И., Малина В.П. // Кокс и химия. 2010. № 12. С. 2.

4. Boenigk W., Gilmet G.H., Schnitzler D. // Light Metals 2002: Proceedings of the International Symposium on Enabling Technologies for Light Metals and Composite Materials and their End-Products. Montreal, Canada. 2002. P. 519.

5. Андрейков Е.И., Красникова О.В., Амосова И.С. // Кокс и химия. 2010. № 8. С.39.

6. Бейлина Н.Ю. Структурные преобразования пеков при взаимодействии с углеродными наполнителями: автореф. дис. ... докт. техн. наук. М., 2000. 53 с.

7. Kuznetsov P.N., Kuznetsova L.I., Buryukin F.A., Marakushina E.N., Frizorger V.K. // Solid Fuel Chem. 2015. V. 49 P. 213. 
8. Kuznetsov P.N., Marakushina E.N., Kazbanova A.V., Kolesnikova S.M., Kuznetsova L.I., Buryukin F.A., Kositcyna S.S. // Amer. J. Appl. Sci. 2016. V. 13. № 1. P. 7.

9. Takanohashi T., Shishido T., Kawashima H., Saito I. // Fuel. 2008. V. 87. P. 592.

10. Yoshida T., Li C., Takanohashi T. // Fuel Proc. Tech. 2004. V. 86. P. 61

11. Takanohashi T., Shishido T., Saito I. // Energy Fuels. 2008. V. 22. P. 1779.

12. Technical and economical assessment of mild coal extraction. Subcontract No 2691-UK-DOE-1874. Final report. University of Kentucky. Center for Applied Energy Research and New Carbon LLC. Consortium for premium carbon products from coal. October, 2005. $30 \mathrm{c}$.
13. Stansberry P.G., Zondlo J.W., Wombles R.H. // Light Metals. 2001. P. 581.

14. Калечии И.В., Коробков В.Ю., Головин Г.С. // ХТТ. 1994. № 1. С. 36.

15. Кричко А.А., Гагарин С.Г., Макарьев С.С. // ХТТ. 1993. № 6. С. 27.

16. Маракушина Е.Н., Кузнецов П.Н., Бурюкин Ф.А., Косицына С.С. // Фундаментальные исследования. 2015. № 12. C. 474.

17. Korolev Yu.M., Gagarin S.G. // Solid Fuel Chem. 2003 № 3. P. 13.

18. Скрипченко Г.Б. // ХТТ. 2009. № 6. С. 7.

19. Sobkowiak M., Painter P. // Fuel. 1992. V. 71. P. 1105.

20. Дмитриев М.М., Обуховский Я.М. Краткий справочник коксохимика. М.: Металлургиздат, 1960 $254 \mathrm{c}$. 